\title{
Quantifying the Rate of Release and Escape of Phytophthora infestans Sporangia from a Potato Canopy
}

\author{
Donald E. Aylor, William E. Fry, Hilary Mayton, and Jorge L. Andrade-Piedra
}

First author: Department of Plant Pathology and Ecology, The Connecticut Agricultural Experiment Station, P.O. Box 1106, New Haven 06504; and second, third, and fourth authors: Department of Plant Pathology, 334 Plant Science Building, Cornell University, Ithaca, NY 14853.

Accepted for publication 9 August 2001.

\section{ABSTRACT}

Aylor, D. E., Fry, W. E., Mayton, H., and Andrade-Piedra, J. L. 2001. Quantifying the rate of release and escape of Phytophthora infestans sporangia from a potato canopy. Phytopathology 91:1189-1196.

A means for determining the rate of release, $Q$ (spores per square meter per second), of spores from a source of inoculum is paramount for quantifying their further dispersal and the potential spread of disease. Values of $Q$ were obtained for Phytophthora infestans sporangia released from an area source of diseased plants in a potato canopy by comparing the concentrations of airborne sporangia measured at several heights above the source, with the concentrations predicted by a Lagrangian Stochastic simulation model. An independent estimate of $Q$ was obtained by quantifying the number of sporangia per unit area of source at the beginning of each sampling day by harvesting diseased plant tissue and enumerating sporangia from these samples. This standing spore crop was the potential number of sporangia released per area of source during the day. The standing spore crop was apportioned into time segments corresponding to sporangia concentration measurement periods using the time trace of sporangia sampled above the source by a Burkard continuous suction spore sampler. This apportionment of the standing spore crop yielded potential release rates that were compared with modeled release rates. The two independent estimates of $Q$ were highly correlated $(P=0.003)$, indicating that the model has utility for predicting release rates for $P$. infestans sporangia and the spread of disease between fields.

Additional keywords: atmospheric spore transport, disease forecasting, inoculum source strength, modeling, potato late blight, turbulence.
Potato late blight, caused by Phytophthora infestans (Mont.) de Bary, is one of the most destructive diseases of potato on a worldwide basis. The recent resurgence of the disease due to the arrival in various locales of more aggressive strains (including the second mating type) of the pathogen (12-14) underscores the need for renewed and improved management guidelines. Fungicides are an important component of the overall management strategy of late blight in most temperate rain-fed production systems. The need for fungicides in late blight control spurs a continuing search for the most efficient methods to utilize fungicides. The importance of weather to disease development has long been recognized, and decision rules based on temperature and moisture conditions in the field have been developed and integrated into disease warning systems $(9,16,18,32)$.

In addition to variable weather, variation in the occurrence of the pathogen has contributed significantly to the sporadic nature of late blight. In many locations in the United States during the 1980s, the pathogen was not detectable. Clearly, forecasts could be improved if they included knowledge of presence or absence of the pathogen in an area. As long as $P$. infestans remains exclusively asexual in a production region, there are two primary mechanisms by which the oomycete can occur in a field: via infected tubers (either surviving from the previous year or unintentionally planted) and via aerial transport of sporangia from outside sources. Long-distance transport of infected tubers by people is well documented, and several forecasting systems predict with varying accuracy the initial occurrence of late blight when infection comes from a soilborne tuber.

Corresponding author: D. E. Aylor; E-mail address: Donald.Aylor@po.state.ct.us

Publication no. P-2001-1003-01R

(C) 2001 The American Phytopathological Society
Currently lacking is a method to predict quantitatively whether sporangia from a source outside a field will be transported to that field, and if transported, whether those sporangia will initiate disease. The best approach for doing this is to employ a quantitative model of aerial spore dispersal. A critical quantity for determining the atmospheric dispersal potential of sporangia is the release rate, $Q$ (spores per square meter per second), of spores from the plant canopy into the atmosphere (2). A direct measure of $Q$ for spores is very difficult to obtain. Recent work has shown that Lagrangian Stochastic (LS) particle trajectory simulation modeling (6) can produce accurate estimates of $Q$ for spores.

The purpose of this study is to develop an LS simulation modelbased approach for quantifying $Q$ for $P$. infestans sporangia. The method yields an estimate of $Q$ by comparing spore concentrations measured above a source of inoculum, with the concentrations predicted by an LS spore-trajectory simulation model. The model is compared with measurements of the "standing crop" of sporangia in the canopy, determined at the beginning of a spore dispersal event, and apportioned in time according to the changes in relative concentration measured above the source. The model appears to adequately describe the release of sporangia from a potato canopy. Thus, the model has the potential to be an important part of an area-wide decision support system by helping to predict risk of disease spread between neighboring or distant fields.

\section{MATERIALS AND METHODS}

Crop and inoculum source. Field experiments were conducted in 1999 and 2000. In 1999, the experimental plots were located at the Homer C. Thompson Research Farm in Freeville, NY, and in 2000, they were located at the Cornell Animal Science Teaching and Research Center in Dryden, NY. Certified potato seeds (cv. Katahdin) were planted by machine on 7 June 1999 and on 7 July 
2000. At planting, 13-13-13 N-P-K fertilizer was applied at a rate of $1,285 \mathrm{~kg} / \mathrm{ha}$. Plants were hilled on 6 July 1999 and 24 July 2000. The distance between rows was $0.86 \mathrm{~m}$, and plants were spaced approximately $0.23 \mathrm{~m}$ apart within the row. One-time applications of the herbicides metribuzin (Lexone) at the rate of $0.28 \mathrm{~kg} \mathrm{ha}^{-1}$ and sethoxydim (Poast) at the rate of 1.8 liter ha ${ }^{-1}$ and the insecticide esfenvalerate (Asana XL) at the rate of $0.63 \mathrm{~kg} \mathrm{ha}^{-1}$ were made in each year.

The experimental potato plot in 1999 consisted of 14 rows, $18.5 \mathrm{~m}$ long, oriented in a north-south direction. The area surrounding the field was almost flat. The only obstacles to the wind near the field were some hedgerow trees $\approx 22 \mathrm{~m}$ to the west and a few scattered trees along the bank of small brook $\approx 10$ to $30 \mathrm{~m}$ to the east. The experimental potato plot in 2000 consisted of 22 rows, $91 \mathrm{~m}$ long, oriented in an east-west direction. The area surrounding the field was almost flat and there were no obstacles to the wind near the field for $\approx 100 \mathrm{~m}$ in almost all directions, except for a corn field $(\approx 2.1 \mathrm{~m}$ tall) located approximately $30 \mathrm{~m}$ to the north of the northern edge of the plot. Wind directions from the north did not occur during the experiments.

The $P$. infestans isolate (US940480) used to inoculate the plots for the 1999 experiments was an A2 mating type belonging to the US-8 clonal lineage, obtained from the collection at Cornell University (Forbes, 1998; no. 113). For the experiments in 2000, isolate US990025, a member of the US-11 clonal lineage (A1 mating type), was used for the inoculations. Sporangia for the experiment were produced on detached leaflets of a susceptible cultivar. The inoculum was prepared by washing the sporangia from the lesion with distilled water. The sporangial suspension was held at $4^{\circ} \mathrm{C}$ for 1 to $2 \mathrm{~h}$ to induce zoospore formation. The suspension was immediately diluted with sterile distilled water, and the concentration of the sporangia was adjusted with a hemacytometer just before inoculation.

In 1999, a 5-m-diameter circular area of potatoes was inoculated at sunset on 2 August with $400 \mathrm{ml}$ of a sporangial suspension of 150 sporangia per $\mathrm{ml}$. The center of the source was located about $5 \mathrm{~m}$ from the north and west edges of the field. To enhance infection, the field plot was irrigated with an overhead sprinkler system for half an hour just before the inoculation. To protect against infection of plants outside of the source area, chlorothalonil (Bravo WS) was applied on 5 August at the rate of $1.3 \mathrm{~kg}$ a.i./ha in water to the noninoculated area of the field. The field was sprayed with Bravo WS a second time on 12 August. Fungicide was applied with a hand-held $\mathrm{CO}_{2}$ pressurized backpack sprayer. In 2000, two 5-m-diameter circular source areas, centered on each

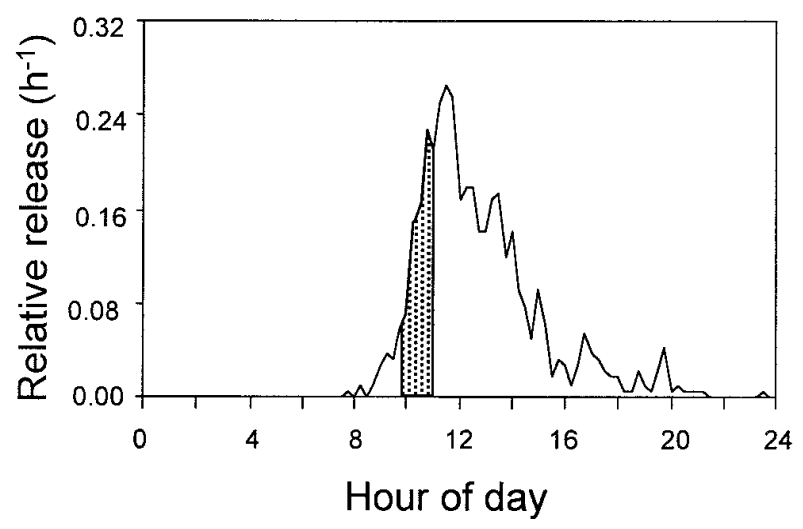

Fig. 1. Diurnal pattern of relative spore release per hour indicated by the Burkard sampler. An estimate of the average rate of sporangia release (spores per square meter per second) during a sampling period (e.g., during the period indicated by the shaded area) was obtained by first multiplying the "standing" spore crop for the day by the fraction of the total released during the period and dividing by the length of the sampling period. of two Rotorod spore-sampling towers were inoculated on 18 August. The centers of these circular inoculated areas were located midway between the 11th and 12th row of potatoes, with one located approximately $15 \mathrm{~m}$ east and the other one approximately $15 \mathrm{~m}$ west of the lengthwise center of the field. As part of another study, the middle four rows of the plot, which were oriented perpendicular to the prevailing wind direction, were also inoculated. The direction of the wind during the sporangia release measurements was across the rows, and spores from these plants did not contribute significantly to the concentrations indicated by the Rotorods.

Leaf area of canopy. The leaf area of the potato canopy was assessed twice in 1999 and twice in 2000. Plants were selected randomly and were destructively sampled to determine leaf area. The number of stems and leaves was recorded for each plant, and the area of leaves on these plants was measured with an area meter (Model LI-3100; LiCor Environmental, Lincoln, NE). The leaf area index (LAI) for the crop was estimated by multiplying the average leaf area per plant and the number of plants per unit of ground area in the field. In 1999, LAI was determined on 6 August (eight plants sampled) and on 16 August (four plants sampled). In 2000, LAI was determined on 24 and 30 August, with eight plants sampled on each date.

Standing crop of sporangia in the source. Each morning, before the dew dried from the plants (usually before 7:30 to 8:00 a.m.) on 8 through 13 August 1999, four sites within the 5-mdiameter circle were sampled to obtain the number of sporangia per unit of ground area within the potato canopy. For this assessment, the canopy was broken into two strata: 0 to 40 and $>40 \mathrm{~cm}$. The total number of lesions within a $0.25-\mathrm{m}^{2}$ grid was counted at each of the four sites in both the lower and upper canopy. At each of the four sites, three to five lesions were destructively sampled to assess sporulation per unit area. Digital images were taken of each lesion sampled by a digital camera (Model D500L; Olympus Corporation, Lake Success, NY). The lesion areas were then measured using UTHSCA Image Tool software (University of Texas, San Antonio). Sporulation of each lesion was assessed by washing off the spores and counting them with a hemacytometer $(8,29)$. The same procedure was used in 2000 , but with some of the samples coming from the line source outside of the $5-\mathrm{m}$ circular areas.

Airborne concentrations of sporangia. Aerial concentrations of $P$. infestans sporangia, $C$ (sporangia $\mathrm{m}^{-3}$ ), were measured above the spore sources by Rotorod spore samplers with retracting-type sampling heads (Model 82; Sampling Technologies, Inc., Los

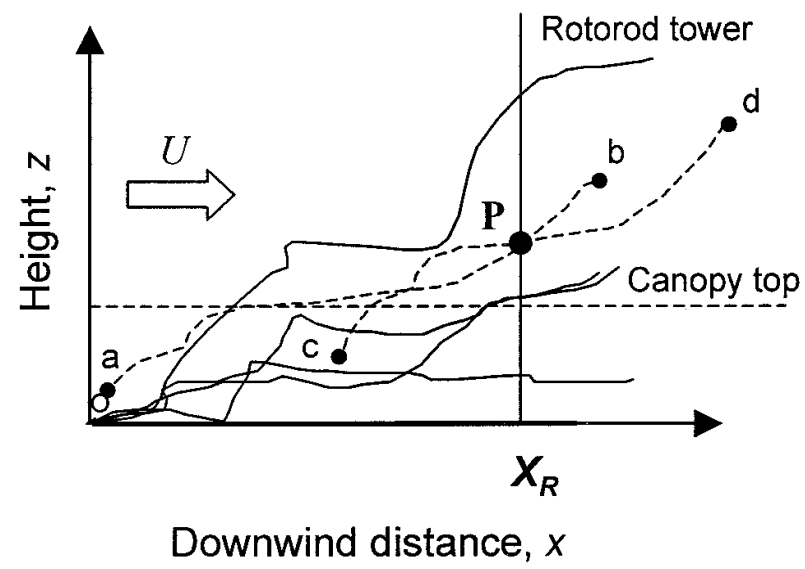

Fig. 2. Schematic of trajectories (solid and dashed irregular lines) calculated by the Lagrangian Stochastic model. Sporangia can be released anywhere in the canopy (e.g., at points a and c) and follow trajectories (e.g., $\mathrm{a}$ to $\mathrm{b}$ and $\mathrm{c}$ to $\mathrm{d})$ that pass through the rotorod location at point $P(x, z)$. A trajectory ends and a new one is begun when a spore is deposited on plants or on the ground. 
Altos Hills, CA). A vertical sampling array of five Rotorods was supported by a pole and located at the center of a source area. In 1999, the spore collection rods were placed at heights of 0.71 , $1.20,1.68,2.25$, and $2.76 \mathrm{~m}$ above the ground at the bottom of the hill. In 2000, the corresponding heights of the collection rods were $0.75,1.25,1.73,2.29$, and $2.81 \mathrm{~m}$, respectively. The top of the potato canopy during the measurements was at approximately $0.65 \mathrm{~m}$. The Rotorods were operated for $2 \mathrm{~h}$ for each sampling period. At the end of each sampling period, the sampling rods were replaced and a new sampling period began. Three to four 2 -h periods ( 6 to $8 \mathrm{~h}$ of sampling) were carried out on most days.

The sampling surfaces of the Rotorods were coated with a thin layer of high vacuum silicon grease (Dow Corning Corp., Midland, MI). $P$. infestans sporangia deposited on the sampling surfaces were counted with a microscope at $\times 100$ magnification. Counts of sporangia on the Rotorods were converted to spore concentrations by accounting for the proportion of the sample surface that was counted, the sampling rate (38 liter $\left.\mathrm{min}^{-1}\right)$, the duration of the sampling period, and the efficiency of the sampler. The capture efficiency of the Rotorod samplers for $P$. infestans sporangia was $45 \%$ based on previous studies $(3,23)$.

In addition to the Rotorods, a Burkard 7-day volumetric spore sampler (Burkard Scientific Sales, Ltd., Rickmansworth, Hertfordshire, England) was operated continuously near the center of the source in both years. The Burkard sampler was placed on a platform that raised it slightly above ground level so the sampling orifice was approximately $0.75 \mathrm{~m}$ above the ground between hills. The surface of the spore-collecting tape was made sticky with a thin layer of the high vacuum grease. Time marks were made by a needle inserted through the trap orifice to identify the beginning and the end of a sampling period. The tape was changed weekly. The clock of the spore trap kept accurate time to within 30 min or less during the 7-day sampling periods. $P$. infestans sporangia were counted at $\times 200$ in two $0.5 \mathrm{~mm}$ wide strips located near the centerline and running along the length of the sampling tape (i.e., in the direction of the time axis on the sampling tape), and counts were recorded for each 15-min segment.

Potential release rates of sporangia during the sampling periods. To obtain an independent estimate of sporangial release rate, $Q$ (sporangia per square meter per second), during the 2-h Rotorod sampling periods, we used the results from the Burkard continuous 7-day spore sampler to partition the release of the standing spore crop over time. In particular, we used the diurnal pattern of relative spore release indicated by the Burkard to apportion the total standing spore crop into fractions of the total released during specific Rotorod sampling periods. The fraction of the total daily release of sporangia during a sampling period was assumed to be proportional to the fraction of the total area under the Burkard trace that occurred during a Rotorod sampling period (Fig. 1). Thus, the potential rate of sporangia release, $Q_{\text {potential }}$ (sporangia per square meter per second) (e.g., during time a to a'), was obtained in a two-step process: first, the standing spore crop (representing the potential for the entire day) was multiplied by the fraction of the total release that occurred during the sampling period (as indicated by the Burkard), and this number was divided by the duration of the sampling period.

Deposition of sporangia in the canopy. Three replicate greased microscope slides $(25 \times 75 \mathrm{~mm})$ were placed in the canopy during several of the sampling periods. The slides were oriented horizontally, with the greased side facing upward, and placed at $0.37 \mathrm{~m}$ above the ground (bottom of the hill). Each slide was supported by a small wooden stake, and a spring clip was used to grip the end. Deposited sporangia were counted at $\times 100$ in 20 transects $(1 \times$ $22 \mathrm{~mm}$ ) for a total of $440 \mathrm{~mm}^{2}$ per slide. The total number of sporangia, the number of clusters, and the number of sporangia in each cluster were recorded for each transect. Spore concentrations at the locations of the slides were estimated by dividing the area dose (15) per unit of time on the slide by the settling speed, $v_{S}$, of the sporangia.

Meteorological measurements. Wind speed and direction, air temperature, relative humidity, and solar irradiance were monitored continuously near the center of the test site with a data logger (Model 21X; Campbell Scientific, Inc., Logan, UT). Wind speed was measured with cup anemometers (Model 014A; MetOne, Inc., Grants Pass, OR) located at $0.70,1.55$, and $3.25 \mathrm{~m}$ above the ground in 1999. A single cup at $3.25 \mathrm{~m}$ was deployed in 2000. Wind direction was measured with a vane (Model 024A; Met-One) placed $3.25 \mathrm{~m}$ above the ground in both years. Temperature and relative humidity were measured with a probe (Model 207; Campbell Scientific) that was shielded from the sun and located at a height of $2.2 \mathrm{~m}$. Solar insolation was sensed by a pyranometer (Model LI-200S; LiCor Environmental) at a height of $2.4 \mathrm{~m}$. These instruments were sampled at 10 -s intervals and averaged for $1 \mathrm{~h}$.

Turbulence statistics of the wind during the spore release periods was characterized with a three-dimensional sonic anemometer (Research Unit, Gill Instruments Ltd., Lymington, England) placed at $2.5 \mathrm{~m}$ above the ground. The sonic anemometer was sampled at $5 \mathrm{~Hz}$. Average values of the horizontal, lateral, and vertical components of the vector wind velocity $(u, v$, and $w$, respectively) and the variances and covariances between these velocity components were recorded every $30 \mathrm{~min}$ by a data logger. The friction velocity, $u_{*}$ (meters per second), was derived from the covariance of $u$ and $w(1)$, and used to scale wind velocity profiles in and above the canopy (27). The $u_{*}$ is a measure of the ability of turbulent eddies in the atmosphere to mix material in the vertical direction and is a major determinant of the potential for sporangia to escape from the plant canopy. Wind speed profiles were measured during selected periods in and above the potato canopy with a hot-wire anemometer (VelociCalc, Model 8355-3; TSI, Inc., St. Paul, MN). Additional information on the variation of wind speed inside potato canopies was derived from studies by Mattson (19).

LS simulation model. The rate of release of sporangia into the atmosphere, $Q$ (sporangia per square meter per second), was calculated using an LS dispersion model $(5,6,10,31,33)$. The basic LS model used here has been described in detail elsewhere (6). Briefly, the model simulates, numerically, the trajectories of spores released at various locations within the source (Fig. 2). The location of a spore in two dimensions $(x, z)$ as it is carried along a trajectory by the wind is obtained by integrating equations that describe the increments in the along-wind

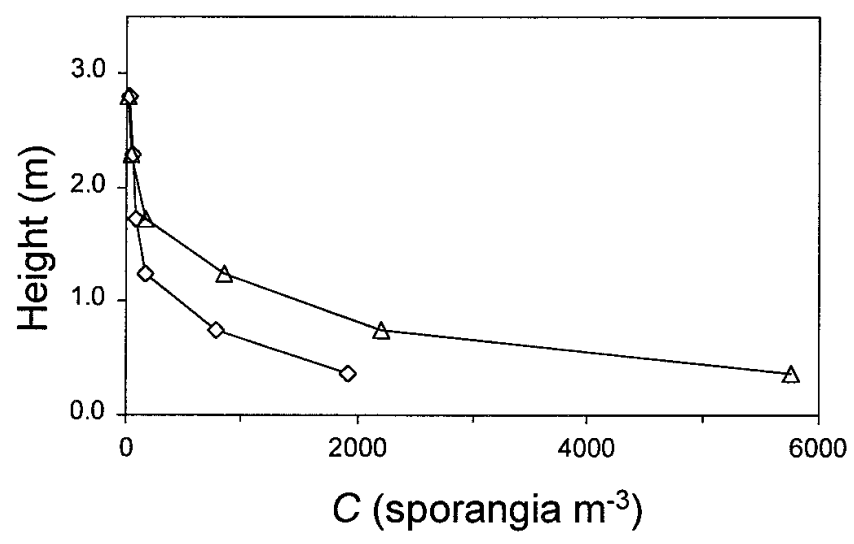

Fig. 3. Typical vertical profiles of Phytophthora infestans sporangia concentration, $C$ (sporangia $\mathrm{m}^{-3}$ ), measured above a source in a potato field. The profiles shown were measured 25 August 2000 (diamonds) during 1245 to 1445 h daylight savings time (DST) and 29 August 2000 (triangles) during 1230 to $1430 \mathrm{~h}$ DST. 
and vertical air velocities $(u, w)$ surrounding a spore over a time step $d t$ :

$$
\begin{aligned}
& d u=a_{u} d t+b_{u} d \xi_{u} \\
& d x=u d t \\
& d w=a_{w} d t+b_{w} d \xi_{w} \\
& d z=\left(w-v_{S}\right) d t
\end{aligned}
$$

where the Langevin coefficients $a_{u}, b_{u}, a_{w}$, and $b_{w}$ are functions of velocity and position; $d \xi_{u}$ and $d \xi_{w}$ are random numbers selected from independent Gaussian distributions, each having average of 0 and variance $d t$; and $v_{s}$ is the settling velocity of the spore in still air. Details about how the Langevin coefficients are to be evaluated are given in Flesch and Wilson (10) and Aylor and Flesch (6). The model was modified slightly to incorporate variations in the crosswind component, $v$, of the wind velocity as described by Flesch et al. (11). Those particular sporangia that follow the trajectories that pass through a differential volume $(d V=d x \times d y \times$ $d z$ ) centered on point $P(x, y, z)$ in the diagram contribute to the concentration of spores at that location. The diagram shows a twodimensional projection of trajectories on the $x-z$ plane.

The probability of a spore being deposited on plants or the ground is calculated during each time step along the trajectory. The probability that a spore will be deposited is expressed in terms of efficiencies based on the spore's settling speed, $v_{S}$, the sizes and canopy air space density of plant elements, and on local wind speed (4-6). If deposited, a new spore is released at one of the source locations and a new trajectory calculation is begun. Otherwise, the spore continues along the trajectory into the next time step, when a new calculation of deposition probability is made.

The LS dispersion model calculates the spore concentration $C_{\mathrm{LS}}$ in a small volume surrounding point $P(x, y, z)$ located at distance $x$ downwind of the leading edge of the spore source and at height $z$ above the ground. When applying the LS model to simulate the concentration in the center $(y=0)$ of a circular area source of radius $R$, we treat the source as a collection of finite crosswind differential area sources with area $\Delta A=\Delta x \times \Delta y$. This requires a slight modification of a two-dimensional model $(6,34)$ to account for lateral (i.e., crosswind) wind velocity fluctuations (11). In the simulations, we released particles at $K \times M$ discreet differential sources located at positions $\left(x_{k}, y_{m}\right)$ upwind of the rotorod tower location where

$$
\begin{gathered}
x_{k}=-\left(\frac{R}{K}\right)(k-0.5) \quad \text { for } k=1 \text { to } K \\
y_{m}=-\left(\frac{R}{M}\right)(m-0.5) \quad \text { for } m=-M \text { to } M \quad m \neq 0
\end{gathered}
$$

\begin{tabular}{|c|c|c|c|c|c|c|c|}
\hline Date & DOY $^{\mathrm{a}}$ & Time $^{b}$ & $T_{\text {air }}\left({ }^{\circ} \mathrm{C}\right)$ & $\% \mathrm{RH}$ & $\mathrm{SR}\left(\mathrm{W} \mathrm{m}^{-2}\right)$ & $u_{*}\left(\mathrm{~m} \mathrm{~s}^{-1}\right)$ & $L(\mathrm{~m})$ \\
\hline \multicolumn{8}{|l|}{1999} \\
\hline 8 Aug & 220 & 0930 & 18.8 & 99 & 57 & 0.14 & 163 \\
\hline \multirow[t]{3}{*}{9 Aug } & 221 & 0800 & 16.4 & 83 & 397 & 0.26 & -29 \\
\hline & & 1230 & 19.5 & 54 & 813 & 0.39 & -40 \\
\hline & & 1445 & 20.0 & 52 & 618 & 0.34 & -35 \\
\hline \multirow[t]{2}{*}{10 Aug } & 222 & 0830 & 15.5 & 87 & 294 & 0.18 & -67 \\
\hline & & 1045 & 18.5 & 65 & 183 & 0.20 & -5 \\
\hline & & 1230 & 23.8 & 84 & 552 & 0.26 & -25 \\
\hline \multirow[t]{3}{*}{12 Aug } & 224 & 0900 & 22.7 & 85 & 579 & 0.22 & -29 \\
\hline & & 1145 & 26.1 & 59 & 859 & 0.36 & -46 \\
\hline & & 1415 & 27.3 & 54 & 680 & 0.35 & -60 \\
\hline \multirow[t]{3}{*}{13 Aug } & 225 & 0745 & 22.4 & 84 & 158 & 0.23 & 392 \\
\hline & & 0945 & 23.2 & 87 & 63 & 0.26 & 64 \\
\hline & & 1200 & 24.5 & 93 & 248 & 0.26 & 88 \\
\hline 26 Aug & & 1300 & 24.6 & 50 & 695 & 0.33 & -79 \\
\hline \multirow[t]{3}{*}{27 Aug } & 240 & 0945 & 20.0 & 89 & 321 & 0.17 & -20 \\
\hline & & 1200 & 24.1 & 69 & 463 & 0.26 & -36 \\
\hline & & 1415 & 24.3 & 67 & 348 & 0.21 & -43 \\
\hline \multirow[t]{3}{*}{$28 \mathrm{Aug}$} & 241 & 0815 & 19.6 & 94 & 401 & 0.18 & -11 \\
\hline & & 1030 & 23.5 & 85 & 632 & 0.36 & -41 \\
\hline & & 1245 & 24.9 & 78 & 613 & 0.34 & -34 \\
\hline \multirow[t]{4}{*}{29 Aug } & 242 & 0800 & 20.4 & 92 & 312 & 0.34 & -189 \\
\hline & & 1015 & 23.4 & 80 & 512 & 0.45 & -97 \\
\hline & & 1230 & 23.9 & 76 & 445 & 0.47 & -106 \\
\hline & & 1435 & 24.1 & 76 & 365 & 0.35 & -75 \\
\hline 30 Aug & 243 & 1100 & 23.5 & 83 & 640 & 0.27 & -20 \\
\hline 31 Aug & 244 & 1045 & 24.4 & 80 & 573 & 0.36 & -34 \\
\hline
\end{tabular}

In the simulations, $N$ particles are released at each $\left(x_{k}, y_{m}\right)$ (to represent release from differential areas of the source that are $\Delta x$

TABLE 1. Values of air temperature $\left(T_{\text {air }}\right)$, relative humidity $(\mathrm{RH})$, solar irradiance $(\mathrm{SR})$, friction velocity $(u *)$, and Obukov length $(L)(1,30)$ during the measured releases of Phytophthora infestans sporangia from a source in a potato canopy

a Day of year.

b Starting time of 2-h sampling period in local daylight savings time. 
$(=R / K)$ meters wide in the along-wind direction and $\Delta y(=R / M)$ meters wide in the crosswind direction), and the concentration at the sensor location (at the center of the source at $y=0$ ) is given by

$$
C_{\mathrm{LS}}\left(x_{\text {sensor }}, y=0, z_{\text {sensor }}\right)=2 \sum_{m=1}^{M}\left[\sum_{k=1}^{K}\left(\frac{Q_{\mathrm{LS}} \Delta x \Delta y}{N \Delta z(2 \cdot \Delta y)} \cdot \sum_{n=1}^{N} \frac{1}{u_{n}}\right)\right]
$$

where $Q_{\mathrm{LS}}$ is the source strength (spores per square meter per second), and $u_{n}\left(x_{\text {sensor }}, y_{\text {sensor }}+\Delta y_{\text {sensor }} / 2, z_{\text {sensor }}+\Delta z_{\text {sensor }} / 2\right)$ is the horizontal spore velocity for spore number, $n$, as it passes $x_{\text {sensor }}$ between $z_{\text {sensor }} \pm \Delta z_{\text {sensor }} / 2$ and $y_{\text {sensor }}+\Delta y_{\text {sensor }} / 2$. For purposes of clarity, we have not cancelled the $\Delta y$ 's in the numerator and denominator in order to make clear that $Q_{\mathrm{LS}} \Delta x \Delta y$ is the release rate (spores per second) from a differential area of the source. Also, we have purposely not cancelled the factors of 2 in order to make clear that, in doing the sum over $M$ in the crosswind direction, we have taken advantage of the symmetry of the problem (the source is assumed to be identical on either side of the centerline), and have summed over half of the domain and multiplied the result by 2 . The physical meaning of the summation over $\left(1 / u_{n}\right)$ in equation 4 represents the reciprocal of an average downwind distance that a spore moves in a time step. This distance, when multiplied by a differential area perpendicular to the $x$ direction, defines an average volume surrounding the sensor that was occupied by a given number of spores during a simulation. This defines a number of spores per unit of volume, which is the local concentration. The upper limit $K$ would be a constant for a rectangular source, however, for a circular source, the upper limit $K$ is a function of $m$ and decreases with lateral distance from the centerline. To simulate the $P$. infestans sporangia sources we used $K=12$ and $M=5$.

The method is to compare $C_{\mathrm{LS}}$ with the concentration of sporangia $\left(C_{\text {measured }}\right)$ measured at location $P(x, y)$. The model
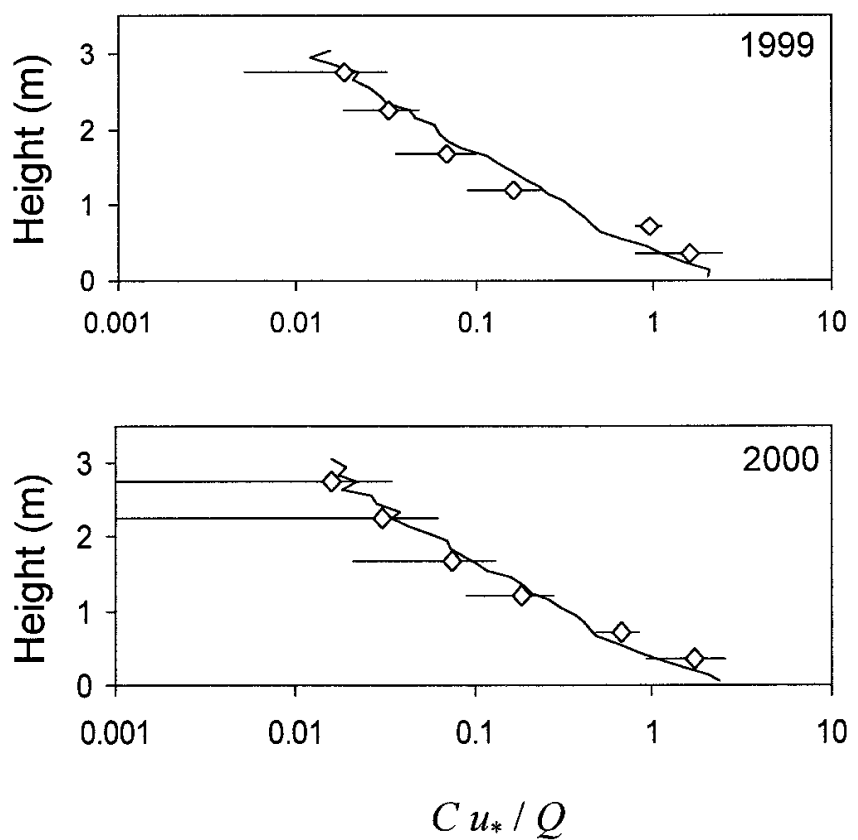

Fig. 4. Vertical profiles of normalized aerial concentration, $C u_{*} / Q$, of Phytophthora infestans sporangia above a source in a potato field during 1999 (average of 16 profiles) and 2000 (average of 21 profiles; the lowest point in the profile was obtained from horizontal slides and is comprised of 14 values). Scaling concentration $(C)$ with friction velocity $\left(u_{*}\right)$ and sporangia release rate $(Q)$ allows concentration profiles for various sporangial release rates and wind speeds to be plotted on the same graph. The symbols provide mean values, and the horizontal bars represent one standard deviation about the mean. The solid lines are given by the Lagrangian Stochastic model with $Q=1$ sporangia $\mathrm{m}^{-2} \mathrm{~s}^{-1}$ and $u_{*}=0.33 \mathrm{~m} \mathrm{~s}^{-1}$. estimate for sporangial release rate, $Q_{\text {model }}$, is found by reconciling the modeled and measured concentrations using the following equation:

$$
Q_{\text {model }}=\left(\frac{Q_{\mathrm{LS}}}{C_{\mathrm{LS}}}\right) C_{\text {measured }}
$$

Our LS model was used to simulate concentrations at the Rotorod locations for each of the sporangia dispersion periods, creating vertical profiles of concentration, $C_{\mathrm{LS}}$, which we compared with $C_{\text {measured }}$ obtained at several heights by the Rotorods. We then scaled these profiles (equation 5) to give values of $Q_{\text {model }}$, which were taken as our estimates of the actual sporangia emission rates. To determine the best estimate of $Q_{\text {model }}$, we used nonlinear estimation to minimize the sum of the squares between the predicted and observed concentrations.

Model parameters. To simulate spore trajectories, the LS model requires as input parameters the settling velocity of the sporangia, the size and area distribution of plant elements in the canopy, and several wind statistics in and above the canopy. The value of the settling velocity, $v_{S}$, of $P$. infestans sporangia used in the model was $0.0085 \mathrm{~m} \mathrm{~s}^{-1}$ (15). The leaf and stem area densities $\left(\mathrm{m}^{-2} \mathrm{~m}^{-3}\right)$ were assumed to be normally distributed with height in the canopy (19). The leaf area index (LAI) for the crop was $\approx 5.4 \mathrm{~m}^{-2} \mathrm{~m}^{-2}$ in both years. As an approximation, we took half of the leaf area to be projected horizontally and half to be projected vertically so that the horizontally projected component of the LAI was 2.7. The characteristic widths of plant elements, which are
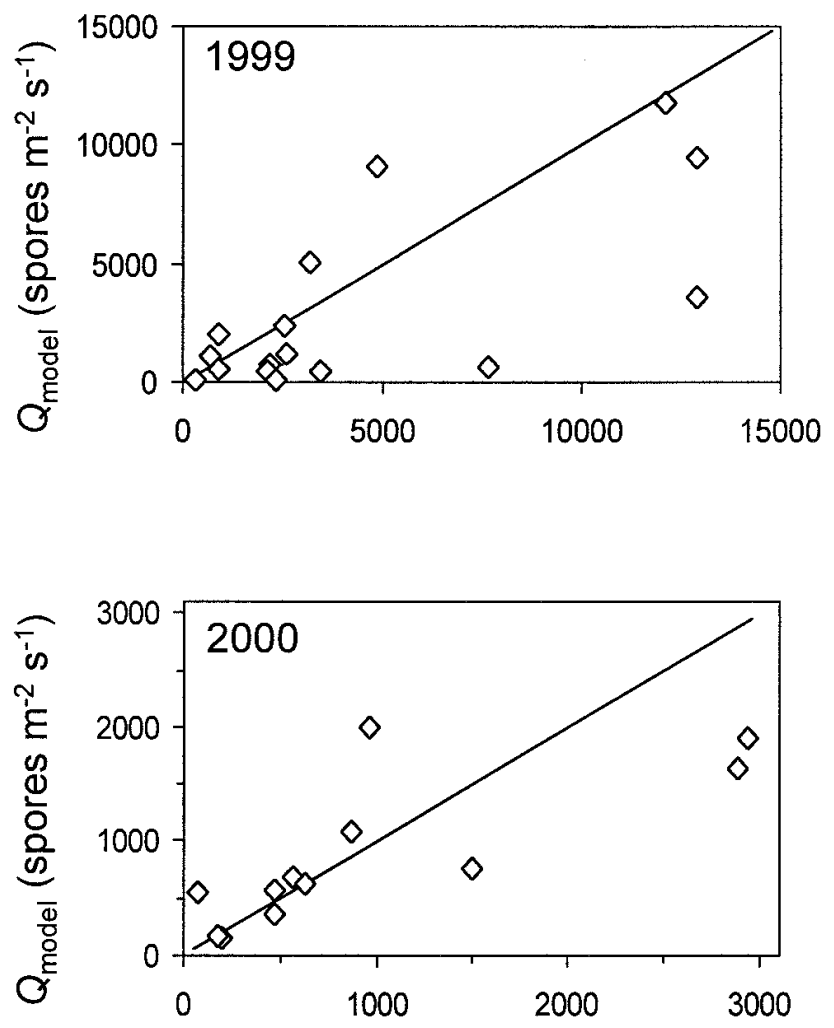

$Q_{\text {potential }}\left(\right.$ sporangia $\mathrm{m}^{-2} \mathrm{~s}^{-1}$ )

Fig. 5. Comparison of sporangial release rates estimated by the model, $Q_{\text {model }}$, and the potential release rates, $Q_{\text {potential }}$, estimated by direct sampling of sporangia on leaves and by apportioning this number using the time course of $C$ recorded by the Burkard (Fig. 1). The solid lines are the 1:1 lines. $Q_{\text {model }}$ and $Q_{\text {potential }}$ were highly correlated in both years; in 1999, the correlation coefficient was $0.70(P=0.003)$, and in 2000 , the correlation coefficient was $0.77(P=0.003)$. 
used for calculating inertial impaction of sporangia on plants, were taken to be $0.03 \mathrm{~m}$ for leaves and $0.01 \mathrm{~m}$ for stems and were assumed constant throughout the canopy. The wind was assumed steady during a sampling period, and we assumed that the release of sporangia was horizontally uniform from the source. We fixed the roughness length and zero-plane displacement height in the model as $z_{0}=0.1 h$ and $d=0.7 h$, respectively, and scaled the wind profiles with $u_{*}(26,27)$. Several properties of the wind are needed to evaluate the accelerations $a_{u}$ and $a_{w}$ in equations 1 and 2 . The required properties are the vertical profiles (as a function of height above the ground) of the time-average horizontal Eulerian wind velocity $U(z)$, the Eulerian velocity variances $\sigma_{u}{ }^{2}$ and $\sigma_{w}{ }^{2}$ and the covariance $\overline{u w}$ (where $u$ and $w$ are the horizontal and vertical components of the fluctuating wind velocity), the gradients $\partial U / \partial z$, $\partial \sigma_{u}{ }^{2} / \partial z, \partial \sigma_{w}{ }^{2} / \partial z, \partial \overline{u w} / \partial z$, and the Lagrangian timescale, $T_{L}$. These statistics were obtained by measurements of wind fluctuations made by the sonic anemometer together with known behavior of wind flow in canopies $(1,6,7,19,24-28,33,35)$.

\section{RESULTS}

Concentration profiles. The aerial concentration of sporangia decreased rapidly with height above the canopy (Fig. 3). Spore concentrations measured by the sampler just above the top of the canopy ranged from 115 to 26,230 sporangia $\mathrm{m}^{-3}$ in 1999 and from 290 to 33,780 sporangia $\mathrm{m}^{-3}$ in 2000 . Wind speeds and friction velocities were somewhat lower in 1999 (median $u_{*}=0.24 \mathrm{~m} \mathrm{~s}^{-1}$, maximum $=0.39 \mathrm{~m} \mathrm{~s}^{-1}$ ) than in $2000\left(\right.$ median $u_{*}=0.29 \mathrm{~m} \mathrm{~s}^{-1}$, maximum $=0.47 \mathrm{~m} \mathrm{~s}^{-1}$ ) (Table 1). Most of the concentration profiles in 1999 and all of them in 2000 were measured during unstable atmospheric conditions $(L<0)$.

The shapes of all of the vertical profiles were similar, which is indicative of the common underlying atmospheric diffusion and transport process that is dispersing the spores. For ease of comparison, the values of $C$ measured at various heights above the ground were standardized by first multiplying them by the friction velocity $\left(u_{*}\right)$ and then dividing by $Q_{\text {model }}$. The data are presented as vertical profiles of height $z$ versus $C u_{*} / Q$ (Fig. 4). The reason for scaling $C$ with $u_{*}$ and $Q$ is that profiles of concentration for various sporangial release rates and wind speeds can be easily compared on the same graph. The values of $u_{*}$ and $Q$ are constant for each sampling period but take on a different value for each spore sampling period. We fitted the LS model results to the measured concentrations by dividing them by a single number, i.e., the modeled sporangial release rate (equation 5). The shapes (slopes) of the measured normalized concentration profiles $\left(C u_{*} / Q\right)$ were described well by the LS model.

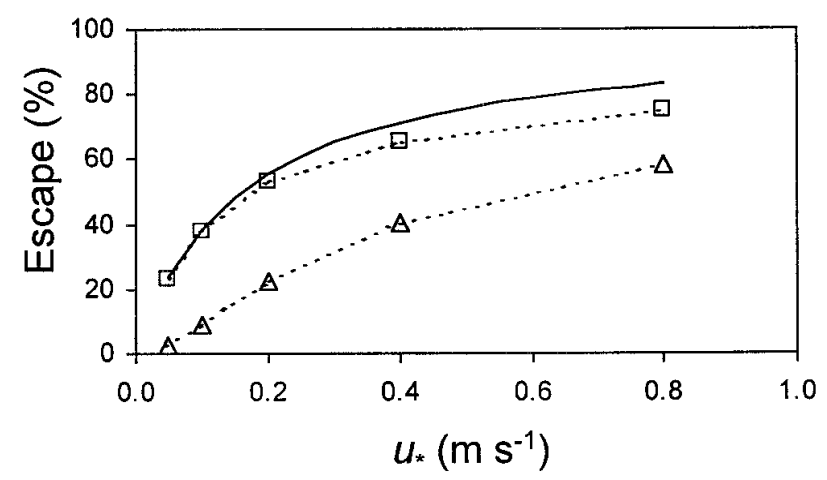

Fig. 6. Escape of Phytophthora infestans sporangia from a potato canopy calculated by the model for sources located in the upper half (squares) or in the lower half (triangles) of the canopy. The equation, escape $=100 /(1+$ $7 f_{x} \mathrm{LAI} \times v_{S}\left(u_{*}\right)$, which is derived elsewhere (4), is shown (solid line) for comparison. The product $f_{x} \mathrm{LAI}$ (set equal to 2.7 ) is the amount of the canopy leaf area per ground area projected in the horizontal direction.
Comparing $\boldsymbol{Q}_{\text {model }}$ with $\boldsymbol{Q}_{\text {potential }}$. By matching the modeled and measured concentrations for each measured profile (equation 5), we obtained a series of values for modeled sporangial release rate, $Q_{\text {model }}$. For each 2 -h sampling period, we also calculated a potential rate of sporangia release per unit of ground area per day, $Q_{\text {potential }}$ (spores per square meter per second). In 1999, $Q_{\text {potential }}$ ranged from approximately 300 to 13,000 sporangia $\mathrm{m}^{-2} \mathrm{~s}^{-1}$, with standard errors of the mean ranging from 9 to $70 \%$ (average $=$ $19 \%$ ). In 2000, $Q_{\text {potential }}$ ranged from approximately 70 to 29,000 sporangia $\mathrm{m}^{-2} \mathrm{~s}^{-1}$, with standard errors ranging from 15 to $42 \%$ (average $=27 \%$ ). There was generally good agreement (Fig. 5 ) between these two estimates of $Q$. $Q_{\text {model }}$ and $Q_{\text {potential }}$ were highly correlated in both years; in 1999, the correlation coefficient was $0.70(P=0.003)$, and in 2000 , the correlation coefficient was $0.77(P=0.003)$. This suggests that the LS model can be used in conjunction with measured concentration values to obtain reasonable estimates of spore release rates that would otherwise be impossible to obtain.

Escape of sporangia from the canopy. The LS model yields estimates for the percentage of sporangia that escape from the canopy (i.e., spores that are transported upward through the $x-y$ plane at the top of the canopy). The model predicts that the escape of sporangia from a potato canopy increases with increasing wind speed and source height in the canopy. Escape of sporangia from the bottom half of the canopy increases from 3 to $59 \%$ as wind speed above the crop increases from approximately 0.5 to $8.0 \mathrm{~m} \mathrm{~s}^{-1}$, whereas escape from the top half of the canopy increases from 23 to $75 \%$ over this same wind speed range. For a given spore and canopy characteristic, escape is sensitive to height of release and to the intensity of atmospheric turbulence, measured here by the friction velocity, $u_{*}$ (Fig. 6).

\section{DISCUSSION}

To predict long-distance dispersal of sporangia of P. infestans, we must first be able to model the initial process of this event, namely the release and escape of sporangia from an inoculum source in a potato canopy. The potato canopy and its effect on wind statistics play an important role in determining escape. Once sporangia are transported well above the top of the canopy, their further dispersal can be described by atmospheric diffusion theory $(1,30)$. This theory has limitations and does not apply to the dispersal near a source and within and just above a crop canopy $(27,28)$. An LS model is the best alternative approach to model dispersal of sporangia in this regime. Our model described well the shape of the spore concentration profiles measured in the field, and it yielded reasonable estimates of sporangial release rates.

For a quantitative evaluation of the model, we compared the model-estimated release rates of sporangia with the corresponding rates estimated from measurements of the crop of sporangia produced in the inoculum source. Measuring spore release rate, $Q$, directly is a practical impossibility for $P$. infestans sporangia, as it is for most spores. We compared model estimates of $Q$ with values derived from the daily standing spore crop. Although we did not achieve perfect agreement, the results are sufficient (Fig. 5) to indicate that the model can be used for investigating the dispersal of $P$. infestans sporangia in a potato canopy and the relative probability of their escaping from the canopy. The model tended to predict values of $Q$ that were, on average, less than those expected from the potential amount indicated by the standing spore crop. This is expected because some of the sporangiophores are likely to dry out and shrink down to the plant surface where their sporangia can be trapped and never leave the canopy.

Canopy structure and spore release height can affect spore escape through their effect on deposition and on exposure to the wind. The choice of the canopy structure (i.e., more erect or more horizontal) has a relatively modest effect on escape. We estimated that approximately half of the canopy LAI was projected horizon- 
tally and half vertically. If, instead, only $30 \%$ of the LAI was projected horizontally, then escape predicted for each value of $u_{*}$ would increase by about $10 \%$. On the other hand, if $70 \%$ of the LAI was projected horizontally, then escape at each value of $\boldsymbol{u}_{*}$ would decrease by about $7 \%$.

The height of spore release in the canopy can potentially have a larger effect on escape. The higher in the canopy the inoculum source is located and the stronger the wind velocity, the greater the number of sporangia that can escape from the canopy (Fig. 6), in qualitative agreement with earlier studies $(4,5,17)$. In the model simulations, sporangia were released from sources centered at two heights in the canopy, $z_{S 1}$ and $z_{S 2}$, which were located at approximately $0.4 h$ and $0.7 h$, respectively. Each simulated trajectory was started within a range of heights $\left(z_{S 1} \pm 0.05 \mathrm{~m}\right.$ or $\left.z_{S 2} \pm 0.05 \mathrm{~m}\right)$ surrounding each release height, with each release height selected from a uniform random distribution to represent the fact that sporangia can be released from many heights in an actual source. Although, in principle, there is no limit to the number of release heights that can be simulated using the model, we do not have sufficiently detailed information on the vertical distribution of sporangia in the canopy to warrant using more levels than we did. The relative difference in spore escape from the two release heights is greatest at low $u_{*}$ (i.e., low turbulence), because, as expected, spores tend to settle out quickly in nonturbulent airflow. The model results support the corollary that a relatively small percentage of the sporangia can escape from the canopy when the source of inoculum is new and located low in a vigorously growing canopy, whereas an increasing percentage can escape as the crop tissue becomes more affected and the canopy begins to melt down.

The model can be used to predict the conditions that enable many sporangia to escape from the potato canopy, and it should be applicable to other systems where spores are released from a source in a canopy during dry conditions. For a given canopy structure and spore release height, spore escape is indicated as hyperbolic function of the ratio of settling speed and friction velocity, i.e., $v_{S} / u_{*}$ (Fig. 6) (4). Logically, small spores in intense turbulence tend to escape more often than heavy spores in low turbulence. Once a simulation model such as the one presented here has been validated, its use, in conjunction with measured spore concentrations and wind speeds, may be the best way to quantify spore release rates. The model requires, as input, the settling speed of the spore, the LAI of the canopy, the shape and orientation of the stems and leaves in the canopy, the friction velocity $\left(u_{*}\right)$, and a measure of atmospheric stability. We used a three-dimensional sonic anemometer to obtain $u_{*}$ and stability. Without the use of a sonic anemometer, it is still possible to obtain estimates of $u_{*}$ and stability from measurements of wind speed and solar irradiance $(1,24,30)$. For neutral atmospheric stability, $u_{*}$ is approximately equal to $10 \%$ of mean wind speed measured well above the canopy $(1,30)$. Thus, when the inoculum source is located in the lower part of the canopy, only about one-third of the sporangia released from the lesions are expected to escape from the canopy when the wind speed is approximately $3 \mathrm{~m} \mathrm{~s}^{-1}$ (Fig. 6). On the other hand, when the source is in the upper part of the canopy, a wind speed of $1.0 \mathrm{~m} \mathrm{~s}^{-1}$ can enable about one-third of the sporangia to escape from this part of the canopy.

In this study, the standing crop of sporangia in the source at the beginning of the day was used as a measure of inoculum source strength. However, this determination is time-consuming, laborious, and incompatible with field surveys for regional forecasting. It is likely that a combination of visual assessments of disease incidence and severity and estimates of sporulation per lesion can supplant this laborious method and eventually enable us to estimate sporulation intensity in the field in a cost-effective and timely manner. Preliminary results indicate that rough field assessments of disease in combination with weather information can be used to provide first approximations of sporangia availability (20;
J. L. Andrade-Piedra, H. S. Mayton, J. Cianchetti, D. E. Aylor, and W. E. Fry, unpublished data). However, our knowledge about sporangia liberation from lesions is still limited. Further studies of the dynamics of source buildup and sporangia liberation should lead to further progress.

The present study has demonstrated that wind speeds of 1 to $2 \mathrm{~m} \mathrm{~s}^{-1}$ are sufficient to remove a sizeable proportion of $P$. infestans sporangia from a potato canopy. These same wind speeds can transport sporangia for 10 to $20 \mathrm{~km}$ in less than $3 \mathrm{~h}$. Successful transmission of disease over these distances depends strongly on sporangial viability. Although relative humidity and air temperature affect survival (21), solar radiation is by far the most important determinant of survival (22). Survival, along with inoculum source strength and spore release, will ultimately dictate disease dispersal distance.

\section{ACKNOWLEDGMENTS}

This study is supported in part by Hatch Funds and by the Cooperative State Research, Education, and Extension Service, U.S. Department of Agriculture, under Agreement 99-34103-7745. We thank P. W. Thiel, R. Plant, B. Pheanious, and J. Cianchetti for excellent technical assistance.

\section{LITERATURE CITED}

1. Arya, S. P. 1988. Introduction to Micrometeorology. Academic Press, San Diego, CA.

2. Aylor, D. E. 1986. A framework for examining inter-regional aerial transport of fungal spores. Agric. For. Meteorol. 38:263-288.

3. Aylor, D. E. 1993. Relative collection efficiency of Rotorod and Burkard spore samplers for airborne Venturia inaequalis ascospores. Phytopathology 83:1116-1119.

4. Aylor, D. E. 1999. Biophysical scaling and the passive dispersal of fungus spores: Relationship to integrated pest management strategies. Agric. For. Meteorol. 97:275-292.

5. Aylor, D. E., and Ferrandino, F. J. 1989. Dispersion of spores released from an elevated line source within a wheat canopy. Boundary-Layer Meteorol. 46:251-273.

6. Aylor, D. E., and Flesch, T. K. 2001. Estimating spore release rates using a Lagrangian stochastic simulation model. J. Appl. Meteorol. 40:11961208.

7. Aylor, D. E., Wang, Y., and Miller, D. R. 1993. Intermittent wind close to the ground within a grass canopy. Boundary-Layer Meteorol. 66:427448.

8. Bashi, E., Ben-Joseph, Y., and Rotem, J. 1982. Inoculum potential of Phytophthora infestans and the development of potato late blight epidemics. Phytopathology 72:1043-1047.

9. Beaumont, A. 1947. The dependence on the weather of the dates of outbreak of potato blight epidemics. Trans. Brit. Mycol. Soc. 31:45-53.

10. Flesch, T. K., and Wilson, J. D. 1992. A two-dimensional trajectorysimulation model for non-Gaussian, inhomogeneous turbulence within plant canopies. Boundary-Layer Meteorol. 61:349-374.

11. Flesch, T. K., Wilson, J. D., and Lee, E. 1995. Backward-time Lagrangian stochastic dispersion models and their applications to estimate gaseous emissions. J. Appl. Meteorol. 34:1320-1332.

12. Fry, W. E., and Goodwin, S. B. 1997. Re-emergence of potato and tomato late blight in the United States. Plant Dis. 81:1349-1357.

13. Fry, W. E., and Goodwin, S. B. 1997. Resurgence of the Irish potato famine fungus. Bioscience 47:363-371.

14. Goodwin, S. B., Smart, C. D., Sandrock, R. W., Deahl, K. L., Punja, Z. K., and Fry, W. E. 1998. Genetic change within populations of Phytophthora infestans in the United States and Canada during 1994 to 1996: Role of migration and recombination. Phytopathology 88:939-949.

15. Gregory, P. H. 1973. The Microbiology of the Atmosphere. 2nd ed. John Wiley \& Sons, New York.

16. Hyre, R. A. 1954. Progress in forecasting late blight of potato and tomato. Plant Dis. Rep. 38:245-253.

17. Ishiguro, K., and Fry, W. E. 1995. Development and sensitivity analysis of a random walk Markovian model for air-borne sporangial dispersal for Phytophthora infestans. (Abstr.) Phytopathology 85:31.

18. Krause, R. A., Massie, L. B., and Hyre, R. A. 1975. BLITECAST: A computerized forecast of potato late blight. Plant Dis. Rep. 59:95-98.

19. Mattson, J. O. 1966. Soil temperatures and light, wind and air humidity conditions of potato crops. Lund Studies in Geography, Ser. A Physical Geography 36, C.W.K. Gleerup Publishers, Lund.

20. Mayton, H., Aylor, D. E., and Fry, W. E. 2000. Quantitative assessment 
of inoculum sources of potato late blight. (Abstr.) Phytopathology 90(suppl.):S50.

21. Minogue, K. P., and Fry, W. E. 1981. Effect of temperature, relative humidity, and re-hydration rate on germination of dried sporangia of Phytophthora infestans. Phytopathology 71:1181-1184.

22. Mizubuti, E. S. G., Aylor, D. E., and Fry, W. E. 2000. Survival of Phytophthora infestans sporangia exposed to solar radiation. Phytopathology 90:78-84.

23. Noll, K. E. 1970. A rotary inertial impactor for sampling giant particles in the atmosphere. Atmos. Environ. 4:9-19.

24. Panofsky, H. A., and Dutton, J. A. 1984. Atmospheric Turbulence: Models and Methods for Engineering Applications, Wiley, New York.

25. Paulson, C. A. 1970. The mathematical representation of wind speed and temperature profiles in the unstable atmospheric surface layer. J. Appl. Meteorol. 9:857-861.

26. Raupach, M. R. 1994. Simplified expressions for vegetation roughness length and zero-plane displacement as functions of canopy height and leaf area index. Boundary-Layer Meteorol. 71:211-216.

27. Raupach, M. R., Antonia, R. A., and Rajagopalan, S. 1991. Rough-wall turbulent boundary layers. Appl. Mech. Rev. 44:1-25.
28. Raupach, M. R., Finnigan, J. J., and Brunet, Y. 1996. Coherent eddies and turbulence in vegetation canopies: The mixing-layer analogy. Boundary-Layer Meteorol. 78:351-382.

29. Rotem, J., and Aylor, D. E. 1984. Development and inoculum potential of Peronospora tabacina in the fall season. Phytopathology 74:309-313.

30. Stull, R. B. 1988. An Introduction to Boundary Layer Meteorology. Prentice-Hall, Englewood Cliffs, NJ.

31. Thomson, D. J. 1987. Criteria for the selection of stochastic models of particle trajectories in turbulent flows. J. Fluid Mech. 180:529-556.

32. Wallin, J. R. 1962. Summary of recent progress in predicting late blight epidemics in United States and Canada. Am. Potato J. 39:306-312.

33. Wilson, J. D., and Sawford, B. L. 1996. Review of Lagrangian stochastic models for trajectories in the turbulent atmosphere. Boundary-Layer Meteorol. 78:191-210.

34. Wilson, J. D., and Shum, W. K. N. 1992. A re-examination of the integrated horizontal flux method for estimating volatilisation from circular plots. Agric. For. Meteorol. 57:281-295.

35. Wilson, J. D., Ward, D. P., Thurtell, G. W., and Kidd, G. E. 1982. Statistics of atmospheric turbulence within a corn canopy. Boundary-Layer Meteorol. 24:495-519. 